\title{
Historicidad y esferas de la vida: el marco de la reflexión moral de la Ilustración escocesa
}

\author{
History and the Spheres of Life: The Framework \\ of Scottish Enlightenment Thought
}

\author{
Julio Seohane Pinilla \\ Universidad de Alcalá
}

Resumen. La historicidad, la adaptación continua de la vida humana a problemas puntuales (sociales, climáticos, económicos...) es el marco -antropológico- en el que la Ilustración escocesa inscribe su reflexión moral. Un trabajo continuo de adecuación al medio generalmente expuesto a través de una concepción por etapas de la historia, cuyo fruto, objetivado como leyes, normas o morales, no es nunca buscado y sí producto de las consecuencias inesperadas de decisiones que se toman sin referentes seguros en su diseño inicial. Esa contextualización, cuyo motor es la perfectibilidad humana, en último término supone la atención a los distintos intereses y esferas de la vida, lo cual hace que la reflexión moral quede parcelada en las pequeñas esferas donde aparecen esos intereses; este será el motivo que llevará a la Ilustración escocesa a buscar algún tipo de universalidad que se complaciera de forma natural en el resultado de aquel artificial proceso de adaptación histórica al medio (la cual se especificará en un sentimiento moral que se complace naturalmente con el bien público).

Palabras clave: Ilustración escocesa; Historicidad; Perfectibilidad; Sentido moral.
ABSTRACT. I would like to expose that historicity, as the continuous process of adaptation of human life to specific problems (social, climatic, economic ...), is the framework where the moral work of the Scottish Enlightenment is built. The endless work of adaptation to the environment (which usually is understood by means of a conception of history by stages) is made without a clear idea or an initial design: our laws, rules, and moral world, are the unintended consequences of decisions made without a previous plan (neither divine, nor rational, nor natural). Such historical process of contextualization, which starts by means of human perfectibility, ultimately involves attention to the different interests and spheres of life. That situation provokes that the moral reflection remains parceled out in the small areas where these interests appear. This is the reason leading to the Scottish Enlightenment to seek some kind of universality which will be found on a moral sense that is naturally pleased with the artificial and historic public good.

Key words: Scottish Enlightenment; History; Perfectibility; Civil Society; Moral Sense.

\section{PRESENTACIÓN}

A través del contraste con la anecdótica y excéntrica afirmación de Lord Monboddo acerca de la "igualdad" entre el género humano y los orangutanes, 
quiero mostrar (apartado 1) que para la Ilustración escocesa lo que realmente caracteriza a la humanidad es su continua composición a través de un proceso histórico que (como se presentará en el apartado 2) se suele concebir como un desarrollo por etapas en las cuales se especifica y hace efectivo el "evidente" fundamento común a los humanos. El motor que pone en marcha este proceso histórico es el perfeccionamiento humano (apartado 3) que no es otra cosa sino un continuo dar cuenta de problemas y situaciones puntuales que acaecen dentro de un contexto cultural, histórico, climático, etc. En este trabajo de adecuación y adaptación al medio no hay planes futuros, ni racionalidad, ni designio divino o natural; por el contrario, es un proceso sumido en la búsqueda de respuestas a cuestiones contingentes sin un plan prefijado en su diseño inicial. Ello fue lo que situó a los ilustrados escoceses en una difícil situación para dar cuenta de cómo tal cambio, sin menoscabar el poso común que une a la humanidad, conducía a la civilización, a la riqueza y bienestar de las naciones, a la "evidente" diferencia entre el hombre civilizado y el salvaje (aun cuando todos comparten el mismo poso de humanidad). Lo curioso del caso es que (como finalizaré en el apartado 4) este decurso de adecuación a problemas puntuales, se desarrolla, por un lado (apartado 4.1), en una vida que atiende a la diversidad cada vez más compleja de los ámbitos -intereseshumanos, haciendo con ello que nuestro mundo moral, social y político se deba concebir a partir de las esferas de actividad específica de nuestra vida cotidiana -sea la familia, la educación, los acuerdos comerciales...-. Por otro lado, la adecuación histórica al medio supone también la total artificialidad del mundo moral, su contextualidad. Con todo (apartado 4.2) la Ilustración escocesa apuesta por una cierta generalidad moral que adviene desde el natural placer que se siente con un buen orden político (que o bien proporciona bien público o simplemente presenta un sistema en el cual es posible vivir de una forma fragmentada y contextual). Este es el sitio en el que la Ilustración escocesa inscribirá su reflexión sobre el sentido moral que es, a la postre, el concepto que aúna a todos estos pensadores por debajo de su patente diversidad. Creo, como concluiré en apartado 5, que estos dos últimos puntos (que el ámbito de la reflexión moral parte de -y no se especifica en- las pequeñas esferas de la vida y que la fragilidad y contingencia de nuestros acuerdos no obsta a su universalidad) nos pueden hoy ser relevantes para entender nuestro mundo moral y político.

\section{LA HISTORIA ES EL LUGAR DE LA HUMANIDAD}

Lord Monboddo siempre fue tenido por un hombre excéntrico. No es que nadie pusiera en duda su rigor intelectual, su serenidad a la hora de emitir juicios 
o la sana sensatez que presidió habitualmente su vida, pero lo cierto es que no dejaba de tener algunas actitudes ciertamente fuera de lo común. No era la menor de ellas su encendida defensa de los orangutanes. O mejor fuera decir su consideración de que pudieran ser tan humanos como los humanos que habitualmente charlaban con Lord Monboddo.

Convencido como estaba, al igual que todos los ilustrados escoceses, de que la naturaleza humana adquiere diferentes modos y variaciones según deba adaptarse al medio físico y social, en cuanto se le presentaba la ocasión no dejaba de señalar que los orangutanes eran seres de nuestro mismo linaje que no habían evolucionado como lo habíamos hecho nosotros debido a las características especiales de su hábitat, pero que, con todo, podrían, si las circunstancias así les hicieran desenvolverse, llegar a un estadio en el que pudiéramos cruzarnos con ellos por la calle y saludarles como si fueran cualquiera de nuestros vecinos. No era este un convencimiento falto de pruebas y Lord Monboddo, de pluma nunca timorata, las aducía sin mengua a partir de los relatos que naturalistas y viajeros traían de remotos lugares que sólo acertaban a vislumbrarse entre los cielos casi siempre encapotados de Edimburgo. Desde ellos creía poder afirmar que los orangutanes tenían un lenguaje que si bien era evidente que no se parecía al nuestro, no dejaba de componer un código que les era muy apropiado para su comunicación. Al igual que Herder haría años más tarde, Lord Monboddo estaba convencido de que los seres humanos tenemos una capacidad innata para comunicarnos de manera lingüística (otorgada graciosamente por nuestro creador), pero que tal capacidad se desarrolla de diferente manera a través del devenir histórico de cada grupo humano. A decir verdad, este era un convencimiento generalizado dentro de la Ilustración escocesa que, también como sería el caso de Herder, subrayaba las capacidades y aptitudes humanas, pero sobre todo el hecho de que cuales fueran aquellas siempre se constituían en un decurso histórico.

Ciertamente este convencimiento ayudaba a la chocante afirmación de Lord Monboddo pues siendo histórico el lenguaje, tan sólo habría que considerar que el de los orangutanes era un lenguaje aún poco evolucionado (y estaba todavía muy cerca de ese tronco común que a todos nos aúna) para tomarlo como un lenguaje tan humano como el que más. No es el del lenguaje el único ejemplo donde Lord Monboddo cree ver que los orangutanes pertenecen al mismo linaje de la humanidad, por supuesto, y quizás sean más deliciosos sus ejemplos morales que nos presentan a aquellos simios como hombres naturales, amistosos, fraternos y concernidos con la vida en comunidad y el bienestar de los suyos, como seres morales en suma (y es una de las mejores razones 
de ello su presentación del pudor de las orangutanas que es similar, y mucho más sincero, que el de las mujeres con las que Lord Monboddo se codeaba en la sociedad escocesa ${ }^{1}$ ).

No creo que haga falta decir nada de la extrañeza con que estas tesis se admitían en sociedad. Ello era así por la evidencia de que los orangutanes no dejaban de ser animales; pero sobre todo porque caso de estar en nuestro mismo orden evolutivo, si se me permite el anacronismo, los orangutanes no eran humanos pues no han tenido historia ninguna. Era esta una argumentación que Lord Monboddo en su apasionada defensa no llegaba a ver situándose, de manera excéntrica, en una perspectiva que no era la escocesa y se parecía más bien a la hoy podemos recoger en Rousseau ${ }^{2}$. Este olvido de que la condición humana se liga a su discurrir histórico también le ocurría cuando obcecadamente defendía el mundo moral y artístico de griegos y romanos argumentando que el orbe clásico había llegado a un punto dentro de la evolución del lenguaje, de las costumbres sociales y de la cultura en general que jamás ha sido superado. Tal afirmación resultaba tan excéntrica como su declaración a favor de los orangutanes, ya que nadie podía imaginarse ni que la historia pudiera detener sus logros ni que el desarrollo histórico no consiguiera siempre la posición que mejor se adaptaba al medio ${ }^{3}$.

${ }^{1}$ Hay que remarcar que la idea de Monboddo no era que los orangutanes representaran un posible estado de naturaleza humana, sino que estaban algo más avanzados que tal estado inicial pues tenían sociedad y reglas morales. Es esto lo que chocará a sus coetáneos en tanto los sitúa ya en el camino de la humanidad: "la conclusión y esencia de todas estas relaciones es que el orangután es un animal de forma humana, tanto por dentro como por fuera; que tienen inteligencia humana, tanta como puede esperarse de un animal que vive sin urbanidad y sin artes; que tiene una disposición mental mansa, dócil y humana; que tiene sentimientos y afectos comunes a nuestra especie, tales como el sentido de la modestia, del honor y de la justicia" (Monboddo 1774: vol. I, 289). Para ver una buena exposición de la apuesta por los orangutanes de Monboddo se puede leer Domsch (2008).

${ }^{2}$ Hay algo que une claramente a Monboddo y Rousseau, como a todos los primitivistas, es su convencimiento de que el hombre salvaje es más sano, enferma menos y afronta con mayor indiferencia las penurias de la vida. Es un espartano fuerte que no se duele por poca cosa y que aun arrostrando la vida sin tanta comodidad como el hombre moderno, es un hombre mucho más sano y menos delicado. Esa imagen de alguna manera también pasará a casi todos los autores escoceses que relatan la vida de los indios americanos (Robertson, Ferguson, también Smith en algún momento o incluso el mismo Hume), mas estos no le darán ni la importancia ni la añoranza que le conceden Rousseau y Lord Monboddo.

${ }^{3}$ Como digo a la excentricidad que suponía su apuesta por los orangutanes, Monboddo añadía su decidida apuesta por la filosofía antigua a la que tomaba como el techo de la reflexión humana. A su parecer no se ha vuelto a pensar con tamaña claridad ni agudeza. Ello queda bien expuesto en los 6 volúmenes de su Antient Metaphysics (Monboddo 1779-1799). 
Si lo que a los convecinos de Lord Monboddo realmente interesaba de la posible historia del lenguaje era que la capacidad lingüística de los seres humanos se constituía en un decurso histórico, ello acontecía de igual manera con el resto de las capacidades humanas que se constituían realmente en el intento de hombres y mujeres por adaptarse con bien al medio en el que se encontraran. De este modo, la historia era el relato de los hechos que han dado lugar al presente en el cual se vive. Un relato que nunca suponía una gran idea de Historia omniabarcante y explicativa completamente a priori; por el contrario la historia universal era el conjunto de la distintas historias de los pueblos -no siempre naciones, ello era importante en Escocia- a través de la que habían llegado a ser como eran. Variaciones climáticas tanto como descubrimientos geográficos o científicos o hábitos sociales y morales incidían de diferente, pero siempre relevante manera en los distintos pueblos; y ello era lo que les hacía evolucionar de un modo particular. Es habitual en este punto citar la rendida admiración de los ilustrados escoceses por Montesquieu, mas, como fuere, lo cierto es que todos consideraban que a través de la historia -también de la historia del lenguaje-se comprobaba la adaptación al medio climático, geográfico, económico o social del género humano (y a diferente medio, como es fácil de imaginar, diferente evolución cultural o nacional). Hay que tener en cuenta que tal comprobación no era a priori, sino que la historia tan sólo daba razón del motivo por el cual estábamos donde estábamos: no había obligación ni de recorrer ningún paso determinado ni de pasar por ningún camino marcado para llegar a adquirir la dignidad humana, por decirlo así. Nuestro desenvolvimiento en el mundo se entiende como adaptación al hábitat, como la búsqueda de una cierta homeostasis; y en el trabajo de encontrarla y tratarla de guardar, sea ello en la civilizada Europa o en la lejana África, es cuando llegamos a expresar toda nuestra humanidad. Ese trabajo se especifica en una Historia.

Resultaba evidente en la época que historias las hay mejores y peores, mas lo que me interesa señalar es que antes de tal calificación está el convencimiento de que histórico es el modo en como la humanidad habita su mundo y que tal modo no compone una sola y única Historia. Los orangutanes, se le dijo en su día a Lord Monboddo, están incrustados en su lugar de vida, no se desenvuelven históricamente. Y lo mismo ocurre con quienes se encierran en la Antient Metaphysics.

\section{LA FORMA DE LA HISTORIA: LA TEORÍA DE LOS CUATRO ESTADIOS}

La Historia sería la presentación de las diferentes etapas por las que una sociedad ha llegado a ser la que en el presente es. Una presentación que por un lado 
se contaba con hechos y, por consiguiente, no era ninguna invención de una mente filosófica, sino un construcción científica que ofrecía el más fiable conocimiento sobre la humanidad en el presente y que, por otro lado, subrayaba que solo hay humanidad cuando se despliega en una historia. Hay que decir, antes de seguir adelante, que en las distintas construcciones históricas que los pensadores escoceses del XVIII alumbraron con su investigación se puede advertir desde la suposición de que todo el recorrido humano se hace bajo la oculta tutela de algún designio o mano invisible que nos lleva a mejor, hasta la presuposición de que el mejor estado, el presente, se alcanza a través de las consecuencias insospechadas surgidas de los distintos intentos por adaptarse y solucionar problemas puntuales; mas lo que me parece relevante es señalar que, aparte de que ambas propuestas se terminan complementando, el presente es un punto que resulta de (y soluciona de la mejor manera) problemas pasados. Como diré a continuación esto lleva a los ilustrados escoceses a sentirse en el "final de la historia", pero al mismo tiempo a reconocer que otros pueblos también están en el final de su historia y merecen un reconocimiento por ello. Soy consciente de que por mor de no entretener mucho mi exposición, en este punto mi vocabulario es ciertamente anacrónico, pero permítaseme continuar mi explicación que creo dará cuenta de tal incomodidad.

Aunque no todos los pensadores escoceses del XVIII se adscribieron a una misma teoría del desarrollo histórico, es habitual reunirlos en torno a una teoría por estadios del desarrollo histórico que habitualmente se suele presentar como una teoría de cuatro estadios; como digo, no todos usaron idéntica terminología, mas sí que estaban convencidos de que el desenvolvimiento histórico organizaba la historia en torno a etapas generales o estadios que a grandes rasgos coincidían con el nomadismo, el pastoreo, la agricultura y la sociedad comercial ${ }^{4}$. Esta gradación suponía una diferente complejidad en las sociedades humanas, pero no por ello se consideraba que unas fueran más humanas que otras (y, por ejemplo, en algunos aspectos morales las "superiores" no siempre eran mejores que las "inferiores"). Ello era así por dos motivos. El primero es que la teoría de los (cuatro) estadios históricos se tomaba como una taxonomía científica y no metafísica, era simplemente un modelo global que organizaba nuestra explicación histórica ${ }^{5}$ que en principio no suponía en ningún caso un dictamen moral. Esto, ciertamente, no siempre resultaba así pues la Escocia del XVIII siempre veía su mundo como la cumbre de la civilización, como el más perfecto de los órdenes sociales (el más civilizado, el que

\footnotetext{
${ }^{4}$ En este punto se puede consultar Meek (1981)

${ }^{5}$ Un "modelo de investigación" lo llama Wences quien explica la teoría de los cuatro estadios con tanto pormenor como claridad en Wences (2009: 158 y ss).
} 
generaba más bienestar) y desde aquí era lógico considerarlo como el mejor de los órdenes morales; pero lo cierto es que en la esencia de una historia que se componía de múltiples factores cuya relación siempre resultaba contingente y no previsible no podía haber un último dictamen moral. El relato histórico se contaba siempre a posteriori y era sólo un relato que nos servía para entendernos mejor (aunque bien es cierto que al reconocernos como resultado de todo un proceso, tendemos a considerar inevitable nuestro presente).

El segundo motivo hace referencia al mismo motor de la variación histórica, la adaptación al medio. Una adaptación (cuyo motor era la perfectibilidad humana) que se entendía sobre todo como una adaptación económica en un sentido amplio. O mejor dicho en un primer sentido de economía: el que nos habla del modo en como nos las componemos de la mejor manera en el lugar en el que estamos, el que refiere al deseo de la humanidad de establecerse del modo más óptimo y feliz en el lugar y tiempo que le hubiera tocado vivir. Era evidente que cada distinto tipo de adaptación generaba una cultura diferente, pero todas eran intentos de solucionar problemas y ninguna suponía una mayor humanidad que otra (en cada momento, en cada contexto, la adaptación feliz era la que tenía valor). Si, por tomar a A. Smith, nuestras naciones tienen un mayor progreso económico y comercial que la de los indios americanos, ello no se debe a que la nuestra sea una raza mejor, que ellos sean menos que humanos o que nuestro Dios nos haya dado mayores bendiciones morales o intelectuales, sino simplemente que para adaptarnos al lugar del mundo que nos ha tocado vivir, hemos debido hacer una serie de modificaciones en nuestro medio que nos han llevado a recorrer de diferente manera nuestra historia. El convencimiento generalizado era que el hombre tiene un poso de perfectibilidad que le hace ir cambiando y creando instituciones y modos de relacionarse diferentes adecuándose al lugar en el que se vive; por esta razón la humanidad se realizaba de diferente manera en cada estadio, mas no dejaba por ello de ser "humanidad".

Se da en este punto una cierta ambivalencia que deseo destacar. Por una parte no son escasas las declaraciones en las que se afirma que el indio, el salvaje, es taimado, vengativo, que le falta todo lo que se puede atribuir a la civilización (desde sensibilidad en el trato amoroso y familiar a habilidad comercial); por otra parte también es común la idealización estoica que toma al indio como alguien digno y libre, capaz de enfrentarse a cualquier decisión

${ }^{6}$ Lo cual es influencia de Pufendorf que no ha sido habitualmente señalada. Lo cierto es que desde Pufendorf emerge una discusión sobre la sociabilidad que tiene su foco en la economía política entendida como adaptación y que tuvo bastante recorrido en la Ilustración escocesa. Sobre el particular se puede consultar Hont (1987). 
moral -incluso a cargo de su propia vida-, imagen que recuerda que si bien el salvaje no tiene una civilización tan compleja como la europea, no dejaba por ello de ser un ser humano que porta incluso cierta nobleza y dignidad moral (la cual se pierde casi de modo irremediable en la moderna sociedad comercial). Ahora no voy a polemizar en este punto (para un mayor pormenor ver Seoane 2015) y baste señalar en este momento que el convencimiento de que la humanidad es histórica sin dejar de tener un poso común permite subrayar tanto un término, la historicidad, como otro, el fundamento común. Es evidente que para una reflexión moral como la que propondrán los ilustrados escoceses que trata de dar cuenta de una sociedad compleja, el hecho de que el salvaje no tenga tal sociedad le sitúa en un grado de inferioridad, pero también es cierto que excepto en el caso más extremo de Hume, los pensadores escoceses del XVIII no renunciaron nunca a suponer una naturaleza común que no alejaba en mucho a hombres de una y otra cultura ${ }^{7}$. Eso sí, frente al primitivismo donde hay ya un "hombre esencial", la idea de Escocia es que esa esencialidad "se va haciendo" y cobrando cuerpo en la historia. Esa historicidad es la que le falta al orangután tanto como al hombre de naturaleza (o a la rendida admiración ante el mundo griego o romano) y por ello Lord Monboddo resultaba un excéntrico ${ }^{8}$ (y quizás esta es la razón de que fuera raro el pensador que no escribiera una Historia bien de Inglaterra, bien de Escocia, bien de América o del mundo o del lenguaje ${ }^{9}$ ).

Tampoco se puede ser ingenuo con la postura escocesa ante la historia pues de un modo subyacente la escritura de una Historia no dejaba de ser un trabajo interesado en dar cuenta de que el presente era el que debía ser. En la medida en que las sociedades humanas son lo que son debido a sus circunstancias, la

${ }^{7}$ En algunos momentos se ha llegado a decir que este es el motivo de que los escoceses que llevaron su esfuerzo colonizador al nuevo mundo en el XVIII se comportaron de un modo menos dado a considerar la supremacía europea que el resto de los colonizadores de origen inglés (Fry 2003: 145-6). En cualquier caso, no son escasas las manifestaciones afirmando que el "salvaje" no es peor - ni mejor- que nosotros. He hablado de la actitud de Smith, pero caben otros ejemplos: "Desde hace mucho tiempo se ha tomado como una máxima incontrovertible que las capacidades del espíritu humano han sido en todos los tiempos las mismas y que la diversidad de los fenómenos exhibida por nuestras especie es simplemente el resultado de las diferentes circunstancias en las cuales los hombres se han encontrado" (Stewart 1854: 69). O "sea que consideremos a la humanidad de acuerdo a la diferencia de sexos, edades, gobiernos, condiciones o métodos de educación, es discernible la misma uniformidad y regular operación de los principios naturales" (Hume 1978: 401). Es la historia la que, al cabo, nos informa que por debajo de la variabilidad, la humanidad es siempre la misma en todos los tiempos y lugares.

${ }^{8}$ El excepcional caso de Monboddo se relata perfectamente en Lovejoy (2007).

${ }^{9}$ Wences (2009: 245-6) apunta que un rasgo común a todos los escoceses fue su preocupación por convertirse en historiadores sociales. 
historia, al mostrar cuáles eran tales circunstancias, daba "razón científica" de por qué los escoceses del XVIII eran como eran y de lo apropiado que les era su presente. De este modo los ilustrados escoceses tenían en la historia la prueba de la adecuación -bondad- de su propio mundo; el lugar en el que estaban era en el que debían estar. Pero, con todo, ninguno se atrevería a negarse como parte de un proceso de constitución histórica de la humanidad donde ninguna parte era superior a la otra siempre y cuando mostrara su equilibrio con su medio respectivo. Claro que en esta tesitura cabe de nuevo la postura de Lord Monboddo: ¿no podríamos considerar que los orangutanes eran hombres muy primitivos, en el primer estadio de nuestra evolución, que dejados en nuestras ciudades podrían llegar a evolucionar hasta convertirse en vecinos nuestros?

\section{PERFECTIBILIDAD E HISTORIA}

La extravagancia de Lord Monboddo podía ser lógica sólo en alguien que no se diera cuenta de que el motor de la historia no era la variación azarosa, sino el impulso de perfectibilidad que es definitorio del género humano. Los orangutanes, como el resto de los animales, están encajados en su hábitat; pueden quizás tener una cultura (unos hábitos sociales, una moral y una dignidad), pero no son perfectibles, no cambian, no mejoran sus condiciones de vida. Posiblemente ello es así porque su hábitat no varía, mas el hecho de que no varie (o de que ellos no lo cambien) es precisamente lo que les aleja de la humanidad. Aun cuando Lord Monboddo señalara moralidad y conductas sociales en los orangutanes, ello no se podía traducir como humanidad pues en su vida está ausente la perfectibilidad que hace humanos a los hábitos sociales y humana a la existencia (posiblemente por ello no han desarrollado un lenguaje como el de los humanos, aun teniendo, a los ojos de Lord Monboddo, los órganos y la capacidad intelectual para hacerlo). En definitiva, los orangutanes no tienen historia y eso es lo que realmente les aleja de la humanidad.

Es necesario advertir de inmediato que no debemos entender la perfectibilidad como un proceso que lleva a la perfección; al igual que la historia no es un camino único y no demuestra nada - tan sólo muestra nuestro camino recorrido-, la perfectibilidad indica únicamente que los humanos al adaptarnos al medio no dudamos en cambiarlo y que una vez la adaptación está alcanzada, no dejamos de buscar algún cambio que mejore la conseguida homeostasis; es esta una ley simplemente descriptiva y que no dice si el camino de perfección es bueno o malo (Oz-Salzberger 1995: 123-4), sino tan sólo que el cambio 
es consustancial al género humano y que signa de humanidad el mundo ${ }^{10}$. Un cambio que por no suponer perfección resultará que puede advenir con desajustes sociales, políticos y económicos -i.e., morales- por lo que nunca resultará extraño, a los ojos escoceses, que buena parte de esa perfectibilidad humana se dirima como luchas o contradicciones sociales que provocan que no haya civilización por sabia que sea que dure eternamente ${ }^{11}$. El perfeccionamiento es lo que marca la distancia que Lord Monboddo no sabía ver; ni siquiera el mundo antiguo era tan estable como él pensaba ${ }^{12}$ y aun cuando resultara estimable, suponía un mundo que ya no era parte del presente que los escoceses del XVIII tenían como suyo.

Resulta ejemplificador el modo en como Boswell relata la llegada del Dr. Johnson a la mansión de Lord Monboddo y el recibimiento entre primitivo y rural que este les ofreció. Cualquier persona civilizada veía con claridad lo pintoresco y lo fuera de la civilización que Lord Monboddo estaba: ofreciendo las virtudes clásicas no se daba cuenta de que estaba fuera de lugar ${ }^{13}$. Como ha expresado hace tiempo A. MacIntyre, las virtudes de los antiguos en el mundo

${ }^{10}$ En suma, no hay humanidad si no hay cambio: "El progreso del comercio tuvo una influencia considerable en el refinamiento de las costumbres de las naciones europeas, y en establecer entre ellas orden, leyes igualitarias y humanidad" (Robertson 1856: 34. Énfasis mío.). Alabanzas similares podemos encontrar en todos los ilustrados escoceses que sentían que era ese comercio el que daba cuerpo a su civilización. No creo que haga falta señalar la relación entre el comercio y el cambio.

${ }^{11}$ La historia no sigue la segura marcha ni de la Razón, ni del divino designio, ni de ningún otro concepto que pudiéramos imaginar (ni siquiera obedece a un sabio legislador); por mucho que podamos confiar en algún tipo de guía invisible, por ser invisible no nos brinda seguridad efectiva ninguna y, como los comerciantes bien conocen, no pocas veces el más rico se arruina y ha de comenzar su camino de nuevo. Es reseñable que en cualquier paseo actual por la ciudad de Glasgow no son pocas las placas conmemorativas a cargo de diferentes comerciantes que desde el XVIII han dado por embellecer la ciudad y en la que se nos cuenta, en la mayor parte de los casos, que se arruinó con su empresa y volvió a construir otra unas veces con el mismo éxito y otras no. Podemos añorar el idílico mundo moral que fundamenta el alabado pudor de las orangutanas, mas ese mundo resulta tan estable que en nada se parece al humano.

12 “Así, Roma, que como toda sociedad emergente había establecido instituciones sencillas, las perfeccionó y las adaptó a las circunstancias; y afinó su sistema político al ajustar las pretensiones de los partidos que surgieron en el Estado" (Ferguson 2010: 177).

13 "Monboddo es un lugar ruinoso, salvaje y desnudo, con una pobre casa antigua; aunque si no recuerdo mal hay dos torres que señalan la residencia del antiguo baron. Lord Monboddo nos recibió en la puerta muy cortésmente [...] su señoría estaba vestido con un traje rústico y lucía un pequeño sombrero redondeado. Nos dijo que ahora le veíamos como el granjero Burnett y que pasaríamos a tomar una cena familiar, una cena de granjero [...] Mostró un talló muy largo de maíz recogido de sus cultivos y dijo 'aquí ven la laetas segetes' " (Boswell 1785: 76-77, carta del 21 de agosto de 1773). 
moderno conservan su nombre, pero han perdido todo su contenido así como el mundo significativo que las daba soporte y fundamento. Cuando Lord Monboddo alaba el mundo antiguo se le puede entender; cuando desea vivir en sus valores, se convierte en alguien ajeno a su propio presente, como un vestigio o una ruina del pasado que ningún encaje efectivo tiene en la vida cotidiana de la Escocia del XVIII. La perfectibilidad no llegó a la mansión Monboddo y de ahí la extrañeza del Dr. Johnson y de todos aquellos que le oían hablar de los orangutanes y de los clásicos (encajados en su hábitat unos y en un pasado remoto otros). Estos últimos habían conseguido un mundo estimable, podían ser dignos de consideración, pero nada tenían que ver con el presente que a los escoceses les había tocado vivir (y si bien eran ejemplo para casi todos los ámbitos de la moral, lo cierto es que ningún tiempo pasado fue mejor). Este es convencimiento generalizado y asumido por todos los ilustrados escoceses; pero, de nuevo, es menester aquí no ser ingenuos ni simplistas ya que este punto nunca dejó de prestarse a cierta ambivalencia.

Efectivamente, en general los ilustrados escoceses eran admiradores del mundo antiguo -y particularmente del idealizado estoicismo romano ${ }^{14}-\mathrm{y}$ debían equilibrar su admiración para no caer en la postura de Lord Monboddo (quien rendido ante los antiguos llegaba a la desestima de nuestro presente). ¿Era posible usar a los antiguos si hablaban para otro modelo de sociabilidad? Las respuestas a este punto nunca fueron claras y sería absurdo buscar homogeneidad o no contradicción al respecto incluso en un mismo autor. Posiblemente lo interesante de los pensadores escoceses fue que eran conscientes de vivir en un mundo moderno y complejo que no siempre casaba con lo que ellos admiraban: todos estaban convencidos de que la sociedad comercial era la más rica, próspera y civilizada etapa de la humanidad, pero ninguno olvidaba que muchos elementos dignos y estimables se han perdido irremediablemente con tal sociedad comercial (lo cual no hacía sencillo el dictamen último a favor del presente).

Estoy convencido de que la tesis de MacIntyre anteriormente señalada (que las virtudes morales clásicas aun cuando conserven su nombre en el mundo

\footnotetext{
${ }^{14}$ Hutcheson tomó mucho interés en traducir a Marco Aurelio, Hume prefería el De Officii a The Whole Duty of Man, Ferguson no dejaba de añorar la virtud republicana de Roma, el espectador imparcial repite en sus exigencias valores estoicos de distanciamiento... Aunque con distinta valoración creo que no es erróneo afirmar que el mundo clásico era muy iluminador para los escoceses del XVIII quienes ni por asomo se plantearían ponerlo a tanta distancia como podía estar el indio americano o los orangutanes. En este punto cabe recordar la tesis de A. Padgen (2002) según la cual el estoicismo - particularmente el romano- prestó herramientas a los hombres de la Ilustración para huir del mecanicismo que acechaba al mundo moral a partir del convencimiento de que las explicaciones causales de la ciencia podían mostrarnos toda la realidad.
} 
moderno han perdido todo su contenido y su mundo de referencia) se comprueba en la añoranza de Ferguson por la fortaleza cívica de los antiguos (o por una milicia que ya nunca encontrará su sitio en el mundo moderno), por la preocupación de Smith al ver que la nueva sociedad comercial arrincona valores morales que le eran muy queridos y por algunos otros casos que revelan que la toma de partido por el presente no siempre fue consistente o sin añoranzas, sino más bien fue conflictiva, a veces desgarradora $\mathrm{y}$, desde luego, siempre estuvo llena de un prudente escepticismo cuando no de una vigilante sospecha. No fue ese el caso, es cierto de Hume ni de Hutcheson, aún demasiado temprano el último para percibir el vaciamiento del cuerpo de virtudes clásicas que se llevaba a cabo con el mundo moderno, quizás deseando ser un mero anatomista el primero; pero en general el mundo escocés del XVIII tenía claro que su presente no dejaba de plantear conflictos entre las alabadas virtudes de los antiguos y las virtudes propias de una sociedad -comercial- moderna. Aun cuando les resultara evidente que su tiempo era el más civilizado de los posibles, las actitudes ante la sociedad comercial siempre suponían variedad de perspectivas ${ }^{15}$. Variedad que, como señala MacIntyre, rompe con la perspectiva teleológica que fundamenta las virtudes clásicas. Incluso aun contando con la preocupación de Smith o Millar (o Ferguson en determinados momentos) por dar con un indicador que permitiera observar un camino más o menos seguro o establecido en la marcha a través de la historia del género humano (que, de paso, estableciera su presente como el más civilizado), se debe reconocer que generalmente nunca se perdió la inquietud ante el presente que se establecía orillando no pocas asunciones morales que a ellos les parecían muy estimables.

\section{UNA HISTORIA DE HUMANA HECHURA: FRAGMENTACIÓN Y UNIVERSALIDAD}

Lo hasta ahora dicho podría haberse planteado desde la convicción de la Ilustración escocesa de que los hombres somos sociales, que por ello nos constituimos en sociedades que se van haciendo cada vez más complejas para dar cuenta de problemas coyunturales y que tal complejidad no supone caos, sino que termina confluyendo, de una manera u otra, en un Sistema estable

15 "Tan grandemente diferentes son los efectos de la opulencia y del refinamiento que al mismo tiempo que arman al rey con un ejército permanente, el mejor instrumento para la tiranía y la opresión, también tienen tendencia a inspirar en el pueblo nociones de la libertad e independencia. Se puede esperar por esto que surja un conflicto entre estos dos partidos opuestos en el cual una variedad de circunstancias puede contribuir a inclinar la balanza a cualquiera de los dos lados" (Millar 2006: 240). 
y organizado. La mejor estabilidad y organización es proporcionada por la sociedad comercial en la que los pensadores escoceses vivían y en la que se abría un espacio conceptual a lo que hoy conocemos como sociedad civil ${ }^{16}$, pero ello no quita para que otros modos sociales si bien no tan complejos, si bien quizás no tan organizados, también sean órdenes humanos en la medida en que cumplan con esa continua adaptación solicitada por las relaciones sociales de la que vengo hablando (i.e., en la medida en que se construyen en un discurrir histórico). Este movimiento que viene llevado por la perfectibilidad es lo que distingue a la humanidad de los animales (es lo que nos hace sociales y no sólo naturales) y lo que hace que los tiempos pasados, por muy excelentes que fueran, sean irrecuperables en la medida en que contestaban a respuestas coyunturales diferentes (lo cual les hace ser vestigio de lo que fuimos, pero no señal de lo que somos). En este punto he querido recordar que si la pérdida -o el alejamiento- de lo natural sólo importa a excéntricos primitivistas, el alejamiento del mundo clásico que solía proporcionar el canon del vocabulario moral, fue más difícil de digerir aunque, en cualquier caso, siempre se estuvo muy lejos de afirmar que algún tiempo pasado fuera mejor que el presente -excepto, de nuevo, en algún caso excéntrico-.

Esta historicidad en la que se resuelve la humanidad también humaniza la historia. En efecto, en abierta oposición a la Primera Parte de la Fábula de las abejas, la historia en Escocia no se concebía bajo la dirección de un director ni de un hábil gobernante ${ }^{17}$, sino que, como ya he expresado

${ }^{16} \mathrm{Ch}$. Berry en diferentes lugares (Berry 2003b y Berry 2010) ha afirmado que en la Ilustración escocesa se abren ciertos modelos de comprensión del mundo social e histórico que podrían apoyar la afirmación de que los ilustrados escoceses ya trabajaban con una idea del mundo social e histórico que abría un espacio conceptual a una clara concepción de la sociedad civil (si bien es prematuro hablar del concepto de sociedad civil en la Escocia del XVIII).

${ }^{17}$ La idea de un hábil gobernante que estabiliza el aparente caos estructural de las sociedades comerciales donde parecen haberse perdido los "fundamentos teleológicos" de las virtudes clásicas, es principal en la Primera Parte de La fábula de las abejas. Mandeville fue realmente el verdadero contraste de los ilustrados escoceses y buena parte de sus planteamientos se entienden con mayor claridad si se ven como un intento de responder al desafío de $L a$ fábula de las abejas. Quizás sea este el motivo por el cual todos terminaron jugando en la liga que Mandeville había establecido, a saber, la de mostrar cómo aparejar y conducir el interés privado con el público. Tolonen (2013) ha mostrado la afinidad entre Mandeville y Hume. En su pormenorizada exposición se puede sacar en claro que la afinidad no sólo es de Mandeville con Hume, sino con el resto de los escoceses (hacia quienes es bien cierto que Tolonen no siente ninguna inclinación) en la medida en que la preocupación y el mundo al que todos miraban eran idénticos: jugaban en el mismo campo, al mismo juego y con los mismos elementos. Ello se hace más evidente cuando nos damos cuenta de que el mismo Mandeville cambió sustancialmente su propuesta en la Segunda Parte de la Fabula de las abejas tras las críticas recibidas principalmente por los autores que aquí nos ocupan. 
anteriormente, los pensadores escoceses consideraban que todas nuestras consecuciones, mejores o peores, han venido tras un largo proceso donde se han reunido muchos y diversos propósitos; todos nuestros logros son fruto de un proceso de sedimentación de intenciones diversas que han cristalizado en lo que ahora tenemos; todas nuestras leyes y reglas civilizatorias son consecuencias no siempre buscadas de largos procesos que se iniciaban sin una idea muy clara de a dónde se quería llegar (tan sólo tratando de dar solución a problemas inmediatos o a muy medio plazo) y que poco a poco se decantaban en las leyes, instituciones y cultura que el presente mostraba. El azar, la casualidad, junto con el ajuste paulatino y no premeditado desde un inicio, es el ámbito en el que se mueve el proceso de perfectibilidad humana ${ }^{18}$ que, de este modo, siempre es meramente humana, sin la seguridad que podría dar una concepción clásica -teleológica- de la humanidad o un resguardo religioso o natural ${ }^{19}$.

Falta una visión de historia futura en el sentido de que aunque realmente es general la aceptación (algo inconsciente en algunos casos, tematizada de manera expresa en otros) de lo que Mandeville instituyó como una argucia de la naturaleza que hacía que todo al final, guiado como por una especie de mano invisible, fuera conducido a un acoplamiento óptimo con el "medio", lo cierto es que ello nunca significó que hubiera un futuro fiable o previsible. Podía ser cierto que alguna oculta argucia natural o divina proveyera para la riqueza de las naciones, pero en cualquier caso la forma que una sociedad próspera pudiera tomar -y los medios por los que efectivamente se llevara a cabo- eran sólo imaginables; sobre ellos no podía haber seguridad

18 "De la misma forma, tampoco desearía dar a entender que los gobiernos han surgido, en general, de la sabiduría política. Por el contrario, casi todos de los que tenemos constancia fueron el resultado de una evolución temporal y de la propia experiencia, de sus circunstancias y de sus emergencias" (Stewart 1856: 419). O como expresa a la perfección John Craig en el prefacio a la edición de 1806 de Ranks de Millar, repitiendo las ideas del mismo Millar. "raramente, si ha ocurrido alguna vez, los sistema generales del Derecho se han formado por la sabiduría prospectiva de los legisladores, por el contrario han aparecido gradualmente, y casi de modo imperceptible, desde el lento progreso de la experiencia humana" (Millar 2006: XXXIV).

${ }^{19}$ El papel que desempeña la religión en la Ilustración escocesa no es algo claro en primera instancia. A todos les es común el convencimiento inicial de que la vida de los seres humanos se ha de instaurar y componer desde posturas no trascendentalistas y una vez ello hecho es cuando se puede hablar de la relación entre la sociedad civilizada y sus creencias religiosas; pero esta idea inicial siempre se ve salpicada de asentidos implícitos que se fundan en convencimientos religiosos y que siempre subsisten y prevalecen bajo un ropaje secular. Miller (2016) ha mostrado esto claramente en el pensamiento de Millar, Ferguson y Hume en el caso que se refiere al matrimonio y avanza la idea de que ello se puede hacer con el resto de los ámbitos de la vida que consideraron los ilustrados escoceses. 
ninguna ${ }^{20}$. Desde esta perspectiva la recurrida "mano invisible" de Smith o la paralela preocupación de Millar en sus Ranks (sólo en esta primera y gran obra, estoy convencido) por encontrar en la historia un hilo conductor que fuera capaz de dar cuenta del momento presente en el cual todos ellos vivían y al que se había llegado tras varias etapas, son en última instancia intentos de comprensión histórica que no implican una concepción fuerte de la Historia capaz de poner todo el pasado en cada momento del presente. Ello supondría, entre otras cosas, que la Historia caminaba por un sendero en el que la lucha entre azar y voluntad, deseo y planificación racional, quedaba soslayada por alguna Razón, Naturaleza o Designio de mayor envergadura a la que un honesto habitante de una sociedad comercial cada vez más compleja pudiera dar su visto bueno ${ }^{21}$.

\subsection{Los pequeños lugares de la vida como ámbito de la reflexión moral}

En este punto hay que recordar algo que resulta fundamental en el pensamiento escocés del XVIII, a saber, que lo que subyace en el fondo de la moralidad es un sentido moral que se complace con el bien público que de alguna manera también resulta, por la curiosa liaçon de los placeres, bien privado. Cómo dar cuenta de ello, de qué manera el placer benevolente se

20 “Al seguir el impulso del momento, al luchar por superar los inconvenientes que padecen o por obtener las ventajas aparentes que están a su alcance, los hombres llegan a fines que no podían prever ni incluso imaginar. Como todos los otros animales, ellos siguen el movimiento de su naturaleza sin percibir su fin. El primero que dijo 'Me apropiaré de este terreno y lo dejaré a mis herederos' no sabía que estaba estableciendo las bases de las leyes civiles y de las instituciones políticas [...] La raza humana está regida, en las instituciones y medidas que adopta, por las circunstancias en que se encuentra; y rara vez se desvía de su camino para seguir el proyecto de un solo hombre. Cada paso y cada movimiento de la humanidad, incluso en las épocas que se conocen como civilizadas, se cumplieron con la misma falta de visión de futuro" (Ferguson 2010: 174).

${ }^{21}$ Se suele pasar por alto, y yo también lo haré en este momento, el hecho de si realmente era cierto que la Escocia del XVIII constituyera una sociedad comercial aun cuando sus pensadores así lo consideraran. Como suele ser habitual en todas las historias, la Escocia de la que vengo hablando se reduce a Edimburgo y Glasgow y todavía quedaba mucho camino por recorrer para lograr reducir a la Escocia tradicional a los cánones de la modernidad. El caso es complejo, como también es complejo el hecho de que nuestros autores se deleitaran, por ejemplo, leyendo a Ossian en inglés y rechazaran cualquier tipo de literatura en gaélico que en su propio tiempo se podía escuchar (Daiches 1964). La situación de Ferguson en este punto es todavía más compleja, pero, como fuere, lo que me interesa es llamar la atención sobre la idealización de Escocia que la historia del pensamiento suele hacer al tratar de la Ilustración escocesa (al igual que, por ejemplo, se idealiza una Francia e incluso un mundo ilustrado francés que realmente era poco más que París). 
equilibraba o trabajaba con el interés particular, es lo que llevó a aquellos hombres a elaborar sus diferentes propuestas; mas como fuere todos partían del hecho de que la vida humana es una vida social en la que se busca felicidad y placer (y de ahí que la acción, el motor de la moral, no sea meramente racional). Puesto que semejante búsqueda no deja de ser un sentimiento que se da en cada individuo, resultaba lógico que tal convencimiento llevara a considerar el mundo social como una compleja relación que coordinaba $-\mathrm{o}$ trataba de coordinar- diferentes historias y lugares en los que la vida tomaba lugar (cada quien expresaría su vida con mayor contento o dedicación en un lugar u otro: en el mundo familiar, en el comercial, en el religioso...). Esto es lo que abre la misma complejidad de la sociedad comercial en la que todos los pensadores escoceses creían vivir; es, realmente, la base misma de la vida social y es el cometido del pensador reflexionar tanto sobre lo que une a los diversos individuos (ello es el marco en el que se inscribe realmente la idea de un sentido moral) como sobre las particularidades donde establecen sus vidas (la efectiva sociedad comercial de la Escocia del XVIII ${ }^{22}$ ). Al cabo si la historia tiene sentido, es porque muestra, con las variaciones, el tronco moral común de la humanidad. Sin este último supuesto, la historia no enseña nada, pero sin la primera evidencia del pequeño cambio continuo y real, la historia ni siquiera puede decir nada.

Una sociedad comercial es una sociedad compleja porque se compone en los diferentes ámbitos del interés humano; todos ellos merecedores de atención pues todos provienen de la diversificación a la que conduce la perfectibilidad humana y todos con una cierta autonomía - con una particular historia se podría decir también-. La Escocia del XVIII comenzaba a ser una sociedad dinámica, donde la uniformidad de la vida pasada cedía el paso a una comunidad hecha de diferentes ámbitos de relación (familiares, educativos, comerciales...) que tenían cada vez más autonomía y relevancia en la vida de los individuos, y quizás ese fue el motivo por el que cobran relevancia sustancial los pequeños lugares de la vida. De este modo si hay algo similar a una mano invisible o a una graciosa providencia es porque es necesario unificar en una visión general (de la historia, de la moral, del buen gobierno) multitud de

\footnotetext{
${ }^{22}$ La misma noción de simpatía que todos toman como uno de los componentes esenciales de la sociabilidad humana, hace referencia a los momentos en que el multiforme comercio humano se desarrolla de un modo tan complejo que es difícil imaginar que lo diverso se una o que su coordinación vaya más allá de un acuerdo tan frágil como impugnable. El mecanismo de la simpatía (frente al de la razón o al del corazón que poco tiempo después se aprestará a sustituirla) simplemente intenta entender y organizar las partes de mejor o peor manera del mismo modo en como hace el comerciante: se trata de saber dónde y con quién se está para obrar en consecuencia de consuno (siempre con el otro en vistas).
} 
pequeños espacios que parecen tener su propia dinámica y relevancia. Ciertamente fue para intentar componer esa innegable e irrenunciable variedad fruto del perfeccionismo histórico del género humano, que la Ilustración escocesa desarrolló un particular juego de útiles morales que le son fundamentales, a saber, la idea de sentido moral, de la simpatía, la misma historicidad del género humano e incluso la idea de un "mercado" que regula y coordina la contingencia y la diferencia. Con tales conceptos se buscaba alguna coordinación a la ya innegable fragmentación del ámbito moral en las esferas en las cuales la vida se establecía.

Hutcheson en este punto oficia de maestro y nos presta el primer y más claro ejemplo de lo que estoy diciendo. Todas sus obras principales presentan, en un momento inicial, una teoría del sentido moral según la cual nos complacemos universalmente con el bien público. Tras ello inmediatamente la reflexión se dirige hacia los pequeños lugares donde se establece el bien público. Estos son repensados a la luz de aquella teoría general del sentido moral. O mejor: son alumbrados -y descubiertos- con la misma. Es el espacio que en todas sus obras se dedica a la vida matrimonial, a la educación de los hijos, a los acuerdos y transacciones comerciales, a la vida política, al mundo religioso, a la judicatura..., dedicación evidentemente necesaria cuando se vive en un mundo parcelado en diferentes esferas de cuya organización advienen distintos bienes ${ }^{23}$. Lo interesante es que los pequeños lugares donde se establece el mundo moral son precisamente los que dan fe de que tal mundo moral es connatural al género humano y lo hace efectivo. $\mathrm{Y}$ dando fe, se establecen como fundamento: no hay moral, podríamos decir, si no persigue establecerse como pequeñas moralidades las cuales, a su vez, demuestran la humana naturaleza moral.

En este momento se podría hablar del modo en como se abre aquí un espacio para que la moral se traduzca en un espacio de "edificación", de constitución de los específicos momentos de la vida, pero me interesa tan sólo mostrar que el camino que he presentado hasta ahora da relevancia moral y social a los ámbitos en los que la vida se construye. Muy distinta al mundo de los orangutanes y del ya pasado y fijado mundo clásico, los escoceses del XVIII concebían su realidad compuesta de diferentes ámbitos todos con su

${ }^{23}$ Esta atención a lo que podríamos llamar ámbito de la moralidad práctica, Hutcheson la legó a toda la Ilustración escocesa. Paradójicamente hasta hace poco no ha llamado mucho la atención de los estudiosos quizás demasiado enfrascados en problemas de mayor altura filosófica (si cabe imaginarlos). Poco a poco ello es algo que se está estudiando cada vez más y buena prueba de ello se puede ver el número monográfico de Journal of Scottish Enlightenment, 11, 1 (2013), dedicado precisamente a esta cuestión. 
particular historia (tan contingente como meditada); estos aunque podían ser comprendidos bajo una teoría general de la moralidad (o del mundo social y político si se quiere decir con palabras contemporáneas), no por ello dejaban de ser relevantes y dignos de ser entendidos en su particularidad. La familia, la educación, los acuerdos comerciales, la legislación militar, la policía, etc., son ejemplos de lugares que cualquier pensador y legislador ha de tener en mente; de la resolución de sus conflictos particulares se forman los materiales con los que se construye el Sistema social (de una sociedad comercial). En buena medida este es el resultado de aquellas esferas de la vida y no ellas el producto de su legislación y hábil coordinación o lo que es lo mismo: la constitución moral -social y política- de la vida humana se hace en la confluencia - no pocas veces conflictiva- de los pequeños ámbitos de la vida.

\subsection{El placer moral natural ante la artificial vida social}

Desde lo anterior creo poder afirmar que el problema de Mandeville cuando negó la Virtud fue precisamente no haber sabido ver que ésta, en un mundo complejo, queda parcelada, fragmentada, definida diferentemente (o con diferentes equilibrios) en los distintos lugares en los que se establece. No es que haya muchas morales, sino que el sentido moral que nos es connatural se especifica en las distintas esferas de la vida de una forma histórica. En este punto realmente hay que tomar algún cuidado porque la posición de los pensadores escoceses del XVIII se sostiene sobre una perspectiva algo lejana a nuestro modo habitual de entenderles en la medida en que para ellos no hay una diferencia clara entre lo natural (lo que la humanidad es por naturaleza, esto es, seres dotados de un sentido moral y que se conforman históricamente) y lo artificial (las distintas maneras en que se especifica el discurrir histórico de nuestra sociabilidad). Ciertamente el largo debate habido entre los comentaristas de este periodo acerca de la naturalidad o artificialidad de las virtudes posiblemente no da cuenta de aquello que era lo esencial del XVIII escocés. Es cierto que hay diferencias en este punto y no pequeñas ( $\sin$ ir más lejos son las que hicieron imposible que Hume consiguiera una cátedra en la Universidad, las que alejan la concepción de la justicia que tiene Smith de la que proclama Hume o las que hacen que Ferguson suene muchas veces como las Highlands que hablan gaélico más que como los comerciantes que en Glasgow y Edimburgo se beneficiaban de la apertura que supuso el Tratado de la Unión con Inglaterra), mas es principal saber que primeramente hay un sentimiento moral que se complace con la felicidad extendida de una sociedad bien ordenada y próspera. Lo natural es el sentido moral que para su complacencia necesita 
de un ordenamiento; que este sea natural o artificial siendo importante no es lo primero. De hecho tal orden social adviene después de una historia que no es fácil especificar y en la que se entremezclan, como ya he dicho, meditados intentos con consecuencias insospechadas; es, podríamos decir, siempre humanamente fabricada. Y tal fábrica es un compuesto difícil de discernir entre lo que la naturaleza o la divinidad ha dado a la humanidad y lo que esta hace con eso que le ha sido proporcionado. El caso es idéntico al que al principio expuse con el intento de dar con la historia de las diversas lenguas; lo que alejaba al género humano de los orangutanes no era que el primero tuviera por naturaleza órganos del lenguaje (pues los simios también los tenían), sino la artificialidad histórica en que se introducía el elemento natural del lenguaje.

Como un buen ejemplo de este convencimiento de que lo natural es complacerse en el bien público que se especifica efectivamente en una historia de artificialidades, quisiera tomar dos casos paradigmáticos en lo que respecta al ámbito de la justicia, a saber el de Hume, quien afirma que la justicia es una virtud artificial, y el de Hutcheson quien, por el contrario, piensa que es natural. Inicialmente dos posturas opuestas que no lo son a poco que reparemos en que para Hutcheson lo natural es complacerse con los actos encaminados al bien público y que aquello que se entiende por bien público se establece precisamente educando a los ciudadanos para que estimen como felicidad unas cosas y no otras lo cual, hasta donde yo alcanzo, es considerar que la misma noción de bien público - la cual queda guardada por la justicia- es artificialmente creada $^{24}$. De este modo llegamos a un lugar que es el de Hume, en el cual la artificialidad de la justicia no es óbice para que sea natural el placer que sentimos con la fabricada ordenación que nos suministra. En este sentido lo artificial nos es natural (Berry 1997: 70) y aunque para Hume la fundación de la moralidad no sea la benevolencia natural hutchesoniana, sí que, sea lo que fuere, es algo propio - natural- de la humanidad.

La artificialidad o no de la justicia, aquello que la crítica generalmente ha tomado como el punto de separación entre Hume y el resto de los pensadores escoceses del XVIII, es algo que hoy nos confunde mucho más de lo que pudo confundir en su día. Es cierto que a partir de Hutcheson los escoceses lo toma-

24 "Cualquier cosa que parezca necesaria para preservar una sociedad amigable entre los hombres [...] debe ser necesariamente exigida por la ley de la naturaleza" (Hutcheson 2007: 112). Lo que es útil en este sentido ha de ser natural por muy artificial que pueda ser; pues aunque sea un artificio humano aparece por una necesidad natural. En este sentido no debe extrañar que Hutcheson en la primera versión de su Investigaciones, donde los actos son benevolentes en la medida en que tienden a la mayor felicidad para el mayor número de personas, diera, con afán newtoniano, tanto espacio a mostrar las reglas matemáticas que regulaban de modo natural la relación entre lo que es útil y la benevolencia -el bien social-. 
rán como un casus belli contra Mandeville y que dieron por ello mucho campo al estudio de con qué actuaciones nos complacemos naturalmente ${ }^{25}$, mas en último término todos juegan ya en el campo que estableció el autor de $L a$ fábula de las abejas: las virtudes ya no pueden ser la clásicas (por mucho que aún conservemos su nombre) y tampoco pueden obtener su fundamento de la divinidad (por mucho que el fundamento de la moral sea un sentido moral que nos ha sido graciosamente dado); las virtudes de las sociedades comerciales son de humana hechura, desarrolladas en un proceso histórico dilatado. En esto radica la extrañeza ante la alabanza de los orangutanes y la desmedida rendición ante el pasado. Pero, además, no se debe olvidar que el objetivo de las virtudes no es desarrollar al hombre con vistas a algún fin, sino conseguir la felicidad que sólo se asegura con una sociedad bien ordenada. Qué sea esta es algo que no se dice nunca con una sola voz, pero no hay divergencia en la convicción de que sea como sea se constituye siempre aprendiendo a reconocer que nos da gusto un determinado comportamiento al que adscribimos bien público o bien social (y, por ende, bien particular). En último término siempre hablamos de artificialidades pues hasta las pasiones de las que Hutcheson hablaba se calmaban y hacían reflexivas de modo artificial a través de relatos que educaban -o presentaban, si se quiere- la benevolencia ${ }^{26}$. En cualquier caso si

${ }^{25}$ Se debiera en este punto tener en cuenta que el mismo Mandeville modificó la segunda parte de La fábula y admitió algunos sentimientos -morales- naturales (precisamente a raíz de la discusión con sus detractores escoceses). También habría que recordar que el "hábil político" que dirige el mundo social y económico en la primera parte de La fábula, se transforma, en la segunda parte, en una apuesta por las consecuencias insospechadas de acciones puntuales en una línea muy similar a la de Ferguson o Millar. Hay una influencia recíproca entre quienes negaban el mundo de Mandeville y la defensa por parte de este de sus posiciones que, como dije anteriormente, termina por establecer un campo de juego muy similar. Si bien las propuestas morales y sociales no son parecidas (excepto en el caso de Hume como muy bien ha expuesto Tolonen), los asumidos terminan siendo similares; así como el mundo para el que pensaban.

26 "Ni la ira, ni el odio hacia el criminal, ni siquiera la justa indignación hacia el mal moral que es natural a todo hombre bueno, deberían ser las únicas fuentes del castigo, sino más bien una atención calmada a los intereses comunes y la salvaguardia del inocente" (Hutcheson 2007: 327). Ha sido A. Broadie quien en diferentes lugares ha insistido en la necesidad de que el sentimiento natural de la benevolencia sea auxiliado por la razón que la da argumentos, relatos y cuentos para calmar y dirigir mejor su natural inclinación hacia el bien común: la reflexión, sin ser ni un sentido externo ni interno, desempeña un papel principal que nos permite discriminar o jerarquizar placeres (Broadie 2009: 351-364). En definitiva, la esencia de la perfectibilidad humana, aquello que nos constituye como hombres, son las afecciones educadas con las que podemos superar "los estrechas ataduras de la vida" (Hutcheson 2007: 82). Desde un punto de vista diferente puede ser ilustrativo Bolla (2013) quien defiende que la misma noción de sentido interno (sea moral o de la belleza o del honor) ya supone un componente noético que como estructura del conocer establece lo que se puede o no sentir. 
bien el fundamento moral puede diferir (y es innegable que Hutcheson piensa que la justicia es una virtud natural y Hume que es artificial), el desarrollo fáctico es siempre el mismo (y la natural benevolencia se cultiva con relatos y narraciones virtuosas y la artificialidad de la justicia no deja de ser el camino natural de organizar nuestro comercio humano) ${ }^{27}$.

\section{A MODO DE CONCLUSIÓN}

Si bien hasta aquí he tomado dos ejemplos, Hume y Hutcheson, que pueden parecer muy claros, considero que este convencimiento se puede extender sin problemas al resto de los pensadores escoceses del XVIII; el espectador imparcial que naturalmente se aloja en mi pecho no deja de necesitar cultivarse, educarse y aprender a calmarse a través de un proceso educativo que termina moldeando con artificio una capacidad natural ${ }^{28}$; del mismo modo se podría proceder con Millar, Ferguson o cualquier otro de los pensadores de los que aquí estoy tratando. Es cierto que este punto precisaría de mayor detenimiento, pero en cualquier caso creo que no es aventurado afirmar que la Escocia del XVIII está convencida de que no nacemos siendo humanos, sino que aprendemos a serlo y, lo más importante, lo vamos siendo en un trabajo social continuo desde el que se desarrolla y constituye efectivamente nuestra natural humanidad ${ }^{29}$. Considerar que la historia es un producto de la sociabilidad

\footnotetext{
${ }^{27}$ Es de destacar que la propuesta más radical de separación entre Hutcheson y Hume, la realizada por Moore (2002), termine afirmando que la diferencia entre ambos estriba en que frente a la benevolencia hutchesoniana, la fundación de la moralidad para Hume es "un sentimiento compartido por toda la humanidad". Ciertamente tal sentimiento es más difícil de acercar a Dios que la benevolencia de Hutcheson, pero ¿acaso no tiene el mismo tipo de naturalidad que esta? Quizás no estaría de más releer la respuesta a esta interpretación que elabora Fate Norton (2005) en la cual Hume y Hutcheson aparecen de un modo mucho más cercano (y con ello une a toda la Ilustración escocesa en un compartido sentimiento acerca de la complejidad del comercio humano). En este sentido también es útil la lectura de Frazer (2010).

${ }^{28}$ Miremos el trabajo del espectador imparcial: nunca su respuesta tiene seguridad absoluta y por ello ha de estar abierta a reelaboraciones que, al cabo, son la única defensa que podemos tener contra la corrupción moral (Broadie 2007: 104). Por ello es importante la instrucción pública; con ella los individuos aprenden tanto la necesidad de reelaborar sus respuestas cuanto las herramientas para llevar a cabo un proceso que nosotros hoy calificaríamos de redescripción continua. Como se expone en la sección final del libro $\mathrm{V}$ de La riqueza de las naciones, la gente instruida cae menos en supersticiones y manejos y, al examinar mejor las diferentes perspectivas ante un problema, resulta más reflexiva (lo cual nos hace más gobernables aunque parezca paradójico).

${ }^{29}$ Esto, como apunta A. Broadie (2012), constituye una de las "agreeable connexions" que se pueden encontrar entre la Ilustración francesa y la escocesa (entre Montesquieu y Ferguson concretamente). Esta fabricación de lo que somos tiene también un ejemplo paradigmático en la
} 
humana en su afán de perfectibilidad es lo que hace radicalmente diferentes a los humanos de los orangutanes y lo que separa el presente del mundo de los clásicos: el tiempo que los escoceses del XVIII tomaban como suyo había especificado la humanidad en un muy diferente Sistema (en distinta organización normativa y moral) que, a la postre, resultaba tan artificial como natural, pues siendo construido provenía de nuestra propia disposición natural y, en definitiva y tal y como apuntó Ferguson, no hay nunca contraste entre la naturaleza y lo artificial pues "el arte es natural al hombre" 30 .

Estoy convencido de que cuando hoy leemos la Escocia del XVIII lo de menos es dirimir si sus pensadores estaban por las virtudes naturales o por las artificiales y cuáles eran unas u otras; lo relevante es considerar que aquellas virtudes, fueran naturales o artificiales, sólo son humanas cuando se especifican en los distintos contextos sociales que han de organizar y para los que son necesarias. Lo natural realmente es que los seres humanos construimos virtudes con nuestros humanos medios, fabricamos nociones de bien público o de riqueza con las que nos vamos a complacer y que reinarán en unas esferas de la vida -social-y no necesariamente en otras ${ }^{31}$. Lo natural, por terminar, es que la humanidad es social, que esta sociabilidad cuando se mueve en un mundo comercial se torna compleja y se termina especificando en los pequeños lugares donde construimos nuestras vida. La universalidad moral, sea una universalidad artificialmente construida o naturalmente obtenida, sólo tiene efecto si se contextualiza en la actividad práctica y no está regida por ninguna

consideración de la mujer como una construcción histórica, tal y como se ve expresamente en el Ranks de Millar, antes bien que como un elemento de la historia natural (al respecto ver O'Brien 2009). Hasta los instintos y las necesidades cambian con la historia como afirma Ferguson para quien, en palabras de Lisa Hill, "aunque las instituciones parten de los instintos de la gente... nuestros instintos originales son modificados y refinados a través del hábito y la experiencia, del conflicto, el juicio y el error" (Hill 2006: 81). En este sentido Berry (2003) apunta que los escoceses estaban convencidos de que somos seres creados por el hábito y la institución y Campbell (1988) pone en claro como la apuesta por un Estado que provea para el bien público con acciones positivas es algo que ya se instituyó en la primera obra de Hutcheson.

${ }^{30} \mathrm{O}$ en palabras de un excéntrico que en lo esencial no dejaba de ser un ilustrado escocés: "aquellos que de la facilidad para hacer algo concluyen que no es una obra del arte sino de la naturaleza, no consideran lo suficiente en qué gran medida los hábitos artificiales están en nuestra naturaleza en el estado presente en el cual estamos y que en esto principalmente diferimos de otros animales" (Monboddo 1774: Libro I, 198).

31 "Tenemos tanto pasiones benevolentes cuanto egoístas; y se recomienda a los moralistas explicar [...] como, si entendemos nuestro verdadero interés, todas nuestras afecciones egoístas conspirarían para persuadirnos en las mismas acciones que la benevolencia nos provoca y que nuestro sentido moral nos determina a aprobar [...] en el estado presente de la naturaleza humana además de nuestro sentido moral y de nuestras afecciones amables, son muy necesarios bastantes motivos adicionales al estudio del bien público (Hutcheson 1735: 29). 
idea más allá del "uso" que se hiciera de tal universalidad; esa es la razón del generalizado convencimiento acerca de que la reflexión ética siempre tiene dos partes, "una que comprende la teoría de la Moral y otra sus doctrinas prácticas" (Stewart 1982); ninguna de las dos partes se deja nunca de mano y la dedicación a ambas es siempre de la misma profundidad; sin la primera no podríamos delimitar nuestro horizonte práctico, sin la segunda perderíamos tanto las normas de conducta para perseguir nuestros fines naturales, como los relatos y la educación que nos ayudan a perseverar en ella.

Considerar que la humanidad se presenta de un modo histórico, que eso la hace diferente de los animales (aun cuando sean excelentes como los orangutanes) y establece cortes tajantes entre las distintas respuestas a distintos mundos (hasta el punto de que aun entendiendo y admirando al mundo clásico lo sabemos lejos de nosotros), es apuntalar un presente que se deleita precisamente en una historicidad fabricada con herramientas meramente humanas que no van más allá de los pequeños lugares en que la vida humana se especifica. Hablo aquí de pequeños lugares y ello no se debe entender como pequeñez moral, sino como espacios más o menos reducidos. La mujer, la infancia, las relaciones mercantiles, posiblemente puedan parecer poca cosa para un gran pensador moral, pero en la Escocia del XVIII no había pensamiento moral si no atendía a los lugares de la acción moral (precisamente porque pensar moralmente era pensar para la acción, para el comercio de la vida que nos lleva a ser esposos, padres, comerciantes, creyentes, patriotas...). Al igual que la historia era el resultado nunca intencionado de mil acciones que se decantaban en un determinado presente, así la moral, el mundo del bien público, no era sino el producto casi azaroso de mil operaciones efectuadas desde las distintas esferas en que el hombre busca establecer una vida compleja. Nos es natural buscar la felicidad y complacernos con el bien público, y esa es la única guía general que tenemos sumergidos siempre en lo pequeño, en esos espacios localizados donde el sentido moral que por naturaleza nos es propio se especifica en las acciones con las que construimos -interesadamente- nuestra felicidad.

\section{BIBLIOGRAFÍA}

Berry, Christopher (1997): The Social Theory of Scottish Enlightenment, Edinburgh, University of Edinburgh Press.

Berry, Christopher (2003): "Sociability and Socialisation" incluido en A. Broadie (ed), The Cambridge Companion to the Scottish Enlightenment, Cambridge University Press. 
Berry, Christopher (2003b): "The Scottish Enlightenment and the Idea of Civil Society" en A. Martins (ed.), Sociedad Civil. Entre mirage e opportunidade, Coimbra, Facultade de Letras (99-115).

Berry, Christopher (2010): “Creating Space for Civil Society”, Giornale di Storia Costituzionale, 20 (49-60).

Bolla, Peter de (2013): "The invention of Concepts: Sense as a Way of Knowing according to F. Hutcheson", Etudes anglaises, 66, 2, 161-170.

Boswell, James (1785): The Journal of a Tour to the Hebrides with Samuel Johnson, London, Henry Baldwin.

Broadie, Alexander (2009): "Hutcheson on Connoisseurship and the Role of Reflection", British Journal for the History of Philosophy, 17, 2, 351-364.

Broadie, Alexander (2012): Agreeable Connexions. Scottish Enlightenment links with France, Edinburgh, Birlinn

Broadie, Alexander (2007): The Scottish Enlightenment, Edinburgh, Birlinn, (2001)

Campbell, Thomas D. (1988): "Francis Hutcheson: 'Father' of the Scottish Enlightenment" incluido en R.H. Campbell \& A.S. Skinner (eds), The Origins and Nature of the Scottish Enlightenment, Edinburgh, John Donald Publishers, p. 167-85.

Daiches, David (1964): The Paradox of Scottish culture: The Eighteenth-Century Experience, London, Oxford University Press.

Domsch, Sebastian (2008): "Language and the Edges of Humanity: Orang-Utans and Wild Girls in Monboddo and Peacock", ZAA, 56.1, 1-11.

Fate Norton, David (2005): "Hume and Hutcheson: The Question of Influence" incluido en D. Garber (ed.), Oxford Studies in Early Modern Philosophy, 2, 211-56.

Ferguson, Adam (2010): Un ensayo sobre la historia de la sociedad civil, Madrid, Akal.

Foerster, Donald M. (1950): "Scottish Primitivism and the Historical Approach", Philological Quaterly, Vol. 29, 1, 307-323.

France, Peter (1985): "Primitivism and Enlightenment: Rousseau and the Scots", The Yearbook of English Studies, Vol. 15, 1, 64-79.

Frankfurt, Harry (2006): La importancia de lo que nos preocupa, Buenos Aires, Katz.

Frazer, Michael L. (2010): The Enlightenment of Sympathy. Justice and the Moral Sentiments in the Eighteenth Century and Today, Oxford University Press.

Fry, Michael (2003): How Scots Made America, Nueva York, St. Martin's Press.

Harkin, Maureen (2002): "Natives and Nostalgia: The Problem of the North American Savage in Adam Smith's Historiography", Scottish Studies Review, vol. 3, 1, 21-31.

Harvey Pearce, Roy (1945): "The Eighteenth-Century Scottish Primitivists: Some Reconsiderations", ELH, Vol. 12, n 3, 203-220. 
Heydit, Colin (2012): The Journal of Socttish Philosophy, 10.1, V-XII.

Hill, Lisa (2006): The Passionate Society. The Social, Political and Moral Thought of A. Ferguson, Dordrecht, Springer.

Hont, Istvan (1987): “The Language of Sociability and Commerce: Samuel Pufendorf and the theoretical Foundations of the four-stages theory" en A. Padgen (ed), The Languages of Political Theory in Early Modern Europe, Cambridge University Press, 1987, 253-276.

Hume, David (1978): A Treatise of Human Nature (edición de L.A. Selby-Bidge), Oxford, Clarendon Press, 1978.

Hutcheson, Francis (1735): Letters Concerning the True Foundation of Virtue or Moral Goodness, London, Wilkins, 1735.

Hutcheson, Francis (1755): A System of Moral Philosophy, Edimburgh/London.

Hutcheson, Francis (2007): Philosophia Moralis Institutio Compendiaria with a Short Introduction to Moral Philosophy, Libro 2, Indianapolis, Liberty Fund.

Johnson, Samuel (1984): A Journey to the Western Islands of Scotland, London, Penguin.

Lovejoy, Arthur (2007): "Monboddo y Rousseau”, Revista de Filosofía (Chile), vol. 63, 171-194.

Meek, Ronald L. (1981): Los orígenes de la ciencia social: el desarrollo de la teoría de los cuatro estadios, Madrid, Siglo XXI de España Editores.

Millar, John (2006): The Origin of the Distinction of the Ranks, Indianapolis, Liberty Fund.

Miller, Nicholas B (2016): "Revealing the "Little Society": Marriage between Sacred History and the Science of Man in Scottish Enlightenment Histories of Civil Society" en R. Lázaro \& J. Seoane (eds.), Religion and Civil Society in the Scottish Enlightenment, Hildesheim, Olms Publishers.

Monboddo, Lord (1774) Of the Origin and Progress of Language, Libro I, Edinburgh, J. Balfour, (1773).

Monboddo, Lord (1779-1799): Antient Metaphysics, Edinburgh, J. Balfour and Co. / London, T. Cadell.

Moore, James (2002): "Utility and Humanity: The Quest for the Honestum in Cicero, Hutcheson, and Hume", Utilitas, 14, 365-86.

O’Brien, Karen (2009): Women and Enlightenment in Eighteenth-Century Britain, Cambridge University Press.

Oz-Salzberger, Fania (1995): Translating the Enlightenment: Scottish Civil Discourse in Eighteenth-Century Germany, Oxford, Clarendon Press. 
Padgen, Anthony (2002): La Ilustración y sus enemigos, Barcelona, Península.

Robertson, William (1856): History of the Reign of Charles the Fifth, Londres, Routledge and Sons, (1769).

Seoane, Julio (2015): "El otro que somos nosotros", incluido en Maria José Villaverde \& Gerardo López Sastre (eds.), Civilizados y salvajes. La mirada de los ilustrados sobre el mundo no europeo, Madrid, Centro de Estudios Constitucionales.

Smith, Adam (1984): The Theory of Moral Sentiments, Indianapolis, Liberty Fund.

Stewart, Dugald (1982): “Account of the Life and Writings of Adam Smith" incluido en A. Smith, Essays on Philosophical Subjects, Indianapolis, Liberty Fund.

Stewart, Dugald (1854): The Collected Works, vol. I, Edinbugh, Thomas Constable and $\mathrm{Co}$.

Stewart, Dugald (1856): Lectures on Political Economy, vol. II, Edimburgh, Thomas Constable and Co.

Tolonen, Mikko (2013): Mandeville and Hume, anatomists of civil society, Oxford, Voltaire Foundation.

Wences, Isabel (2009): Hombre y sociedad en la Ilustración escocesa, México, Distribuciones Fontamara. 